\title{
Vibration Characteristics of Composite Beam Having Flax, Aloevera and Sisal Fibers as Reinforcements
}

\author{
Thomas P, Sreehari VM
}

\begin{abstract}
Composites are highly significant due to their various advantages and natural fibre reinforced composites can be vastly used in automobile and aircraft interior applications. This paper principally deals with natural fibre reinforced composite (NFC) in which flax, aloevera, sisal fibres are selected to be reinforced in epoxy matrix (as inner laminate layers) and is used in combination with glass-epoxy (as outer laminate layers). Such composite beam structures are analysed in Ansys software employing FEM. The comparison for various NFCs is presented by evaluating effect on natural frequency due to various parametric variations like laminate stacking sequence, material hybridization, and presence of cut out.
\end{abstract}

Keywords : Cut out, Dynamic analysis, Finite element analysis, Natural fibre composites.

\section{INTRODUCTION}

Over the past few years, various astounding improvements have been brought about in the field of new structural materials which have caught the attention of researchers to work on various aspects of composite materials. The improved operation and the dependability of the structural system have led to widespread development of the fibre reinforced composite materials and especially bio-composites. The immense interest in natural fibre reinforced composites (NFC) is in view of the significant benefits of these materials, which enhances their usage over several applications.

Several literatures are available related to the physical, mechanical properties of NFCs [1-3]. Properties like flexural and energy absorption, damping of sound and vibration, etc., make natural fibre reinforced hybrid composites good for structural applications [4-6]. Behaviour of aircraft wing structure made of NFC was discussed by Aravind et al. [7]. Meenakshi et al. [8] experimentally analysed the mechanical behaviour of NFCs. Over the years, several analyses have been carried out on the various properties of hybrid composites $[9,10]$, but there are comparatively less works

Revised Manuscript Received on December 30, 2019.

* Correspondence Author

Thomas P*, School of Mechanical Engineering, SASTRA Deemed University, Thanjavur, India.

Sreehari VM*, School of Mechanical Engineering, SASTRA Deemed University, Thanjavur, India.

(C) The Authors. Published by Blue Eyes Intelligence Engineering and Sciences Publication (BEIESP). This is an open access article under the CC BY-NC-ND license (http://creativecommons.org/licenses/by-nc-nd/4.0/) analysing the dynamic properties of these structures. Very few recent works discussed about vibration of natural material based composites [11-12].

The scope of the present work is made and magnified by the rising application of NFC's in the place of synthetic composites in view of the global drive towards a more sustainable future. Natural fibre composites offer a drastic decrease on the ill-effects of manufacturing and synthesis of man-made composites. The ever increasing application of NFCs also motivates researchers to study the vibrational characteristics of these composites. The objective of the present work is to make a detailed comparison of the vibration behaviour of composite beams reinforced with flax, sisal and aloevera fibres. Various parametric studies are performed and the effects of several parameters like presence of cut out on the natural frequency of the NFC beams are presented.

\section{FINITE ELEMENT ANALYSIS}

Finite element analysis is employed in present work using Ansys software. The Shell 281 element is used for discretization. The material properties of the composite beam are represented in Table I. The dimensions of the beam considered are as follows: $l=150 \mathrm{~mm}, b=10 \mathrm{~mm}, h=10$ $\mathrm{mm}$. The natural fibre reinforced glass epoxy composite beam considered in present analysis is ten layered with the natural fibre reinforced in epoxy being in in the middle four layers. Glass-epoxy is stacked symmetrically above and below the natural fibre layer. The laminate stacking sequence of the flax, sisal and aloevera fibre is as shown in Fig 1- 3 respectively. The composite beam was modelled in Ansys and analysed for its natural frequency with several parametric variations.

\begin{tabular}{|l|}
\hline Glass-epoxy \\
\hline Glass-epoxy \\
\hline Glass-epoxy \\
\hline Flax-epoxy \\
\hline Flax-epoxy \\
\hline Flax-epoxy \\
\hline Flax-epoxy \\
\hline Glass-epoxy \\
\hline Glass-epoxy \\
\hline Glass-epoxy \\
\hline
\end{tabular}

\begin{tabular}{|l|}
\hline Glass-epoxy \\
\hline Glass-epoxy \\
\hline Glass-epoxy \\
\hline Sisa-epoxy \\
\hline Sisal-epoxy \\
\hline Sisal-epoxy \\
\hline Sisal-epoxy \\
\hline Glass-epoxy \\
\hline Glass-epoxy \\
\hline Glass-epoxy \\
\hline
\end{tabular}

Fig. 1. Stacking of flax epoxy

Fig. 2. Stacking of sisal epoxy 


\begin{tabular}{|c|}
\hline Glass-epoxy \\
\hline Glass-epoxy \\
\hline Glass-epoxy \\
\hline Aloevera-epoxy \\
\hline Aloevera-epoxy \\
\hline Aloevera-epoxy \\
\hline Aloevera-epoxy \\
\hline Glass-epoxy \\
\hline Glass-epoxy \\
\hline Glass-epoxy \\
\hline
\end{tabular}

Fig. 3. Stacking of aloevera epoxy

Table- I: Material properties of composite beam

\begin{tabular}{|l|l|l|l|l|}
\hline & Glass-epoxy & Flax-epoxy & $\begin{array}{l}\text { Aloevera- } \\
\text { epoxy }\end{array}$ & Sisal-epoxy \\
\hline $\mathrm{E}_{1}(\mathrm{~Pa})$ & $50 \times 10^{9}$ & $10.8 \times 10^{9}$ & $1.58 \times 10^{9}$ & $6.22 \times 10^{9}$ \\
\hline $\mathrm{E}_{2}(\mathrm{~Pa})$ & $20 \times 10^{9}$ & $0.4 \times 10^{9}$ & $6.33 \times 10^{7}$ & $0.24 \times 10^{9}$ \\
\hline $\mathrm{E}_{3}(\mathrm{~Pa})$ & $20 \times 10^{9}$ & $0.4 \times 10^{9}$ & $6.33 \times 10^{7}$ & $0.24 \times 10^{9}$ \\
\hline $\mathrm{G}_{12}(\mathrm{~Pa})$ & $8.97 \times 10^{9}$ & $0.74 \times 10^{9}$ & $3.16 \times 10^{7}$ & $0.12 \times 10^{9}$ \\
\hline $\mathrm{G}_{23}(\mathrm{~Pa})$ & $3.45 \times 10^{9}$ & $0.74 \times 10^{9}$ & $1.26 \times 10^{7}$ & $0.12 \times 10^{9}$ \\
\hline $\mathrm{G}_{13}(\mathrm{~Pa})$ & $3.45 \times 10^{9}$ & $0.74 \times 10^{9}$ & $3.16 \times 10^{7}$ & $0.12 \times 10^{9}$ \\
\hline$\mu_{12}$ & 0.25 & 0.4 & 0.25 & 0.3 \\
\hline$\mu_{23}$ & 0.34 & 0.4 & 0.25 & 0.3 \\
\hline$\mu_{13}$ & 0.34 & 0.4 & 0.25 & 0.3 \\
\hline$\rho\left(\mathrm{kg} / \mathrm{m}^{3}\right)$ & 2081 & 1450 & 1150 & 1250 \\
\hline
\end{tabular}

\section{RESULTS AND DISCUSSION}

\section{A. Effect of Laminate Stacking}

The variation of natural frequency with the laminate stacking is shown in Fig 4. A ten layered composite beam with natural fibres in the middle four layers were assumed. The boundary condition was assumed to be clamped - free. The natural frequency was tested for symmetric and anti-symmetric cross and angle plies.

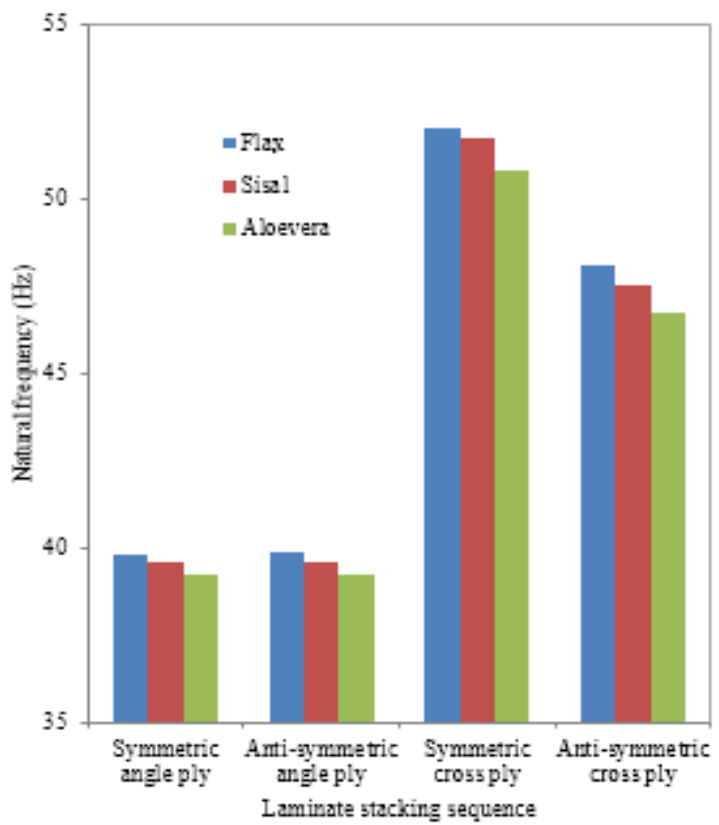

Fig. 4. Variation of natural frequency with laminate stacking sequence
As observed from the results, flax fibre has the highest natural frequency followed by sisal and aloevera for various ply orientations. Symmetric cross ply was seen to have the highest natural frequency followed by the anti-symmetric cross ply. Both symmetric and ant-symmetric angle plies were seen to have significantly lower natural frequencies in comparison with their counterparts. The effect of symmetricity on natural frequency is significant in the case of cross ply laminates whereas it is less significant in the case of angle ply laminates. The result once again enhances the application of symmetric laminates because of their higher natural frequency in addition to the fact that they don't experience any bending coupling. They also don't twist and bend much on cooling after fabrication.

\section{B. Effect of $\mathbf{E}_{1} / \mathbf{E}_{2}$ Ratio}

The variation of natural frequency with $E_{1} / E_{2}$ ratio was analysed on a composite beam of ten layers symmetric cross ply with the inner four layers being natural fibre. The beam was analysed for C-F boundary condition. The $\mathrm{E}_{1} / \mathrm{E}_{2}$ ratio was tested for both thick $(l / h=10)$ and thin beam $(l / h=100)$. The results are presented in Fig 5-6.

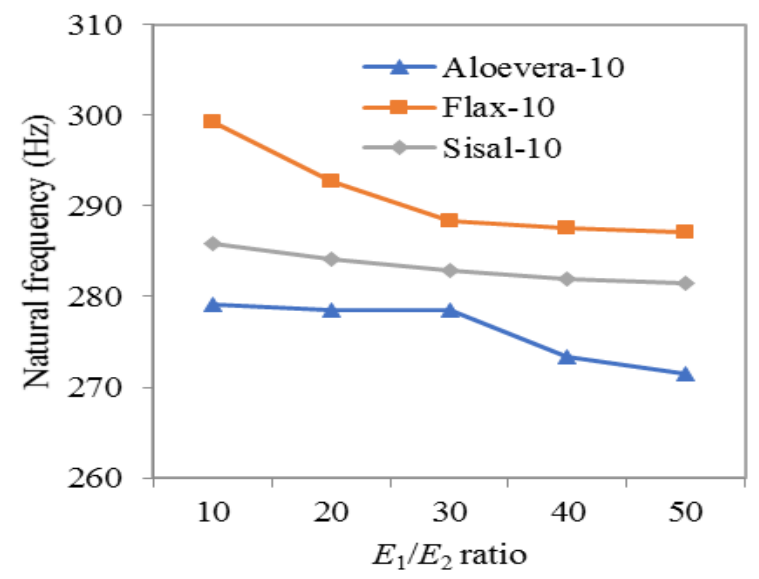

Fig. 5. Variation of natural frequency with $E_{1} / E_{2}$ ratio for l/h $=10$

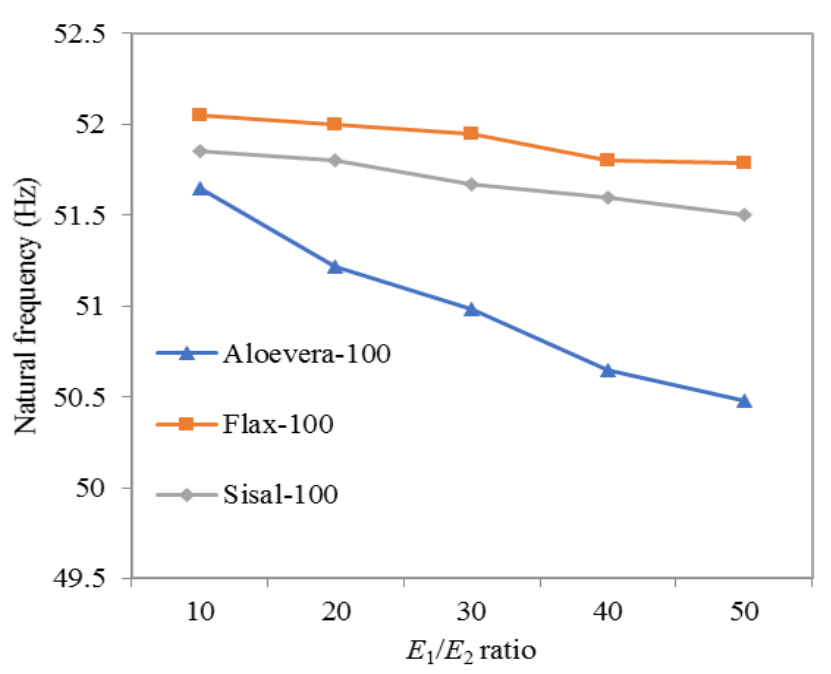

Fig. 6. Variation of natural frequency with $E_{1} / E_{2}$ ratio for $\mathrm{I} / \mathrm{h}=\mathbf{1 0 0}$ 
From Fig. 5 and Fig. 6, it is observed that natural frequency decreases with an increase in $E_{1} / E_{2}$ ratio. The $E_{1} / E_{2}$ ratio is varied from 10 to 50. Flax fibre has the highest natural frequency followed by sisal and aloevera. The decrease in natural frequency is insignificant for thin beams whereas it is comparatively sizable for thick beams. There is a maximum deviation of $4 \%$ as the $E_{1} / E_{2}$ ratio increases. This decrease in natural frequency is owing to the reason that as $E_{1} / E_{2}$ ratio increases, the value of $E_{2}$ and $E_{3}$ also decreases as $E_{1}$ value is maintained constant throughout. As the overall Young's modulus is decreased, the stress acting on the beam decreases which in turn causes the stiffness of the material to decrease. This in turn decreases the natural frequency as they are directly proportional. The mode shapes for flax, sisal and aloevera for thick beam for $E_{1} / E_{2}=50$ are presented in Fig. 7-9.

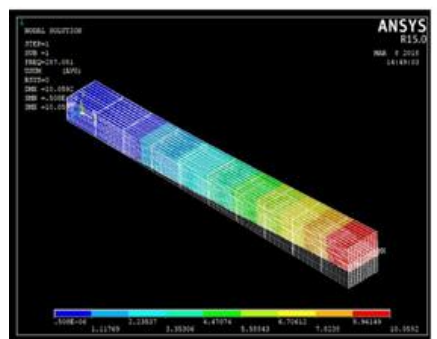

Fig. 7. 1st mode of flax

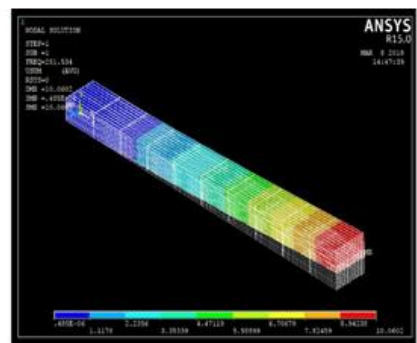

Fig. 8. 1st mode of sisal

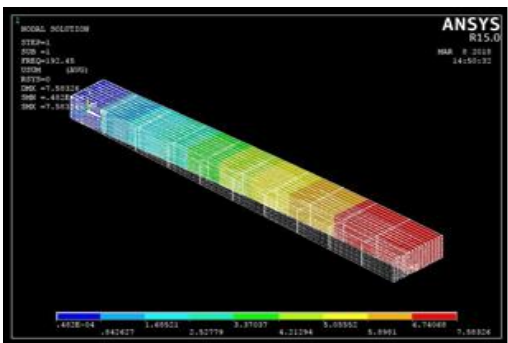

Fig. 9. 1st mode of aloevera

\section{Effect of $\boldsymbol{l} / \boldsymbol{b}$ Ratio}

The variation of natural frequency with length to breadth, $l / b$, ratio is analysed on a composite beam with $l / h$ ratio of 100 with boundary condition C-F. The composite beam analysed is of ten layers with symmetric laminate stacking. The results are presented in Fig. 10.

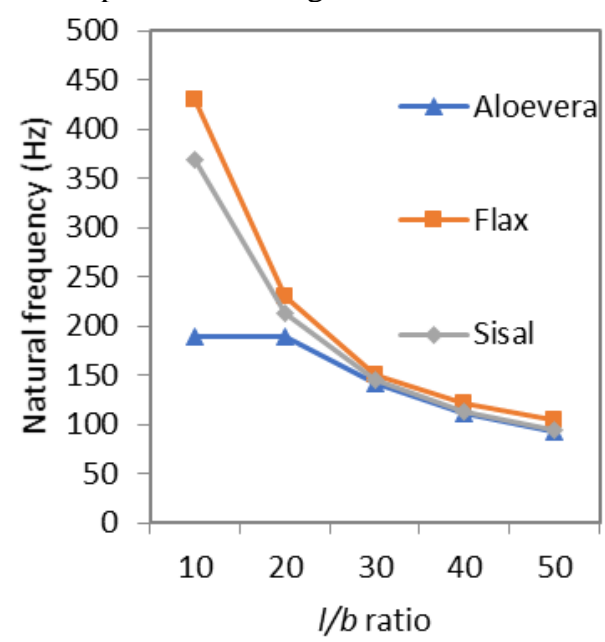

Fig. 10. Variation of natural frequency with $\boldsymbol{l} / \mathbf{b}$ ratio From Fig 10, It can be observed that the natural frequency decreases with an increase in $l / b$ ratio. Flax and sisal fibre shows considerable decrease in natural frequency as the $l / b$ ratio increases from 10 to 20. The magnitude of natural frequency tends to be similar for all three natural fibres as the $\mathrm{l} / \mathrm{b}$ ratio increases further. The rate of decrease in natural frequency is lowest for aloevera fibre. As $l / b$ ratio increases, the natural frequency decreases because of the decrement in stiffness of the composite beam. The corresponding mode shapes for aloevera for $l / b$ ratio of 10 and 50 is shown in Fig. $11-12$

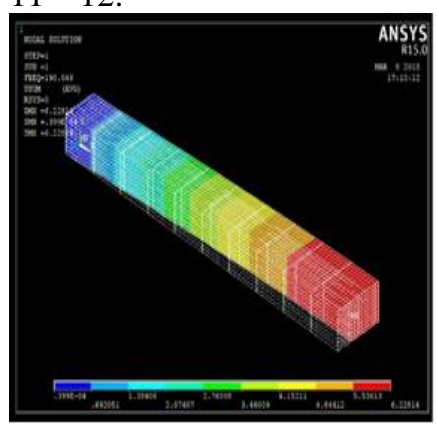

Fig. 11. Aloevera $l / b=10$

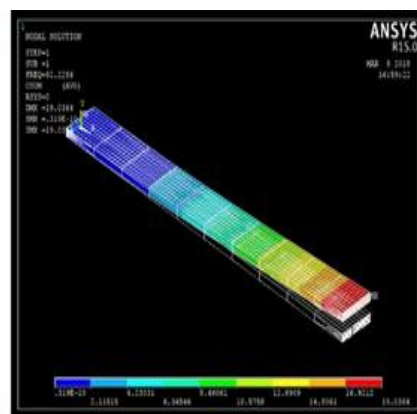

Fig. 12. Aloevera $l / b=5$

\section{Effect of Circular Cut-out}

The variation of natural frequency with variation in diameter of cut to breadth of beam, $d / b$ ratio, of a circular cut-out on a composite beam of $l / h$ ratio of 10 is analysed and the results are presented in Fig. 13. The breadth is maintained constant at $10 \mathrm{~mm}$.

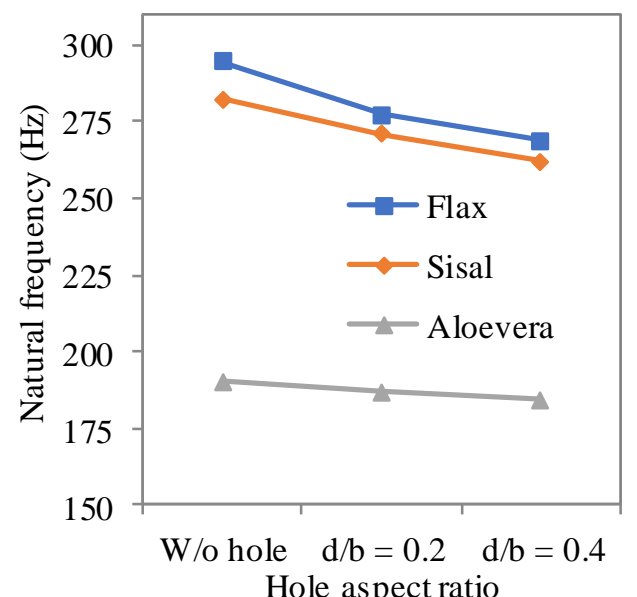

Fig. 13. Variation of natural frequency with hole aspect ratio

From Fig 13, it can be observed that the natural frequency decreases with an increase in $d / b$ ratio. Flax and sisal fibre shows considerable decrease in natural frequency as the $d / b$ ratio increases whereas the similar decrement in natura frequency is smaller in aloevera fibre. As $d / b$ ratio increases, the size of the circular cut-out increases which leads to a loss of material in the composite beam. This leads to a decrease in stiffness of the composite beam which in turn decreases the natural frequency. The corresponding mode shapes for all three fibres for a $d / b$ ratio of 0.4 is shown in Fig. $14-16$. 

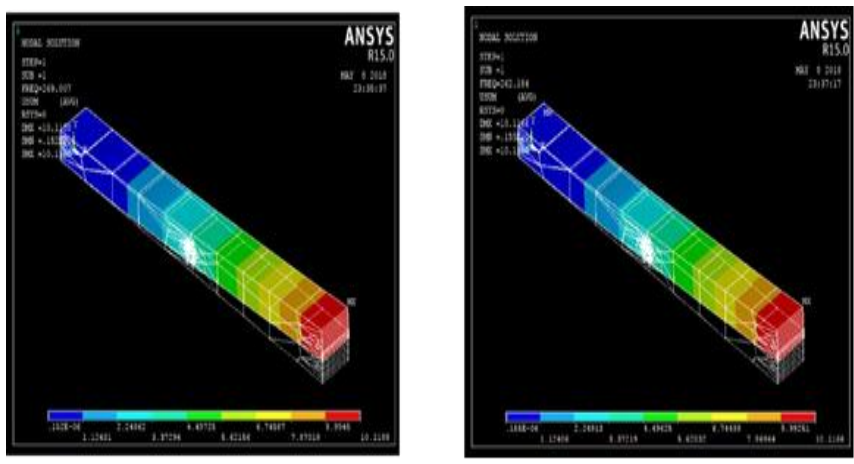

Fig. 14. Flax with $d / b=0.4$

Fig. 15. Sisal with $d / b=0.4$

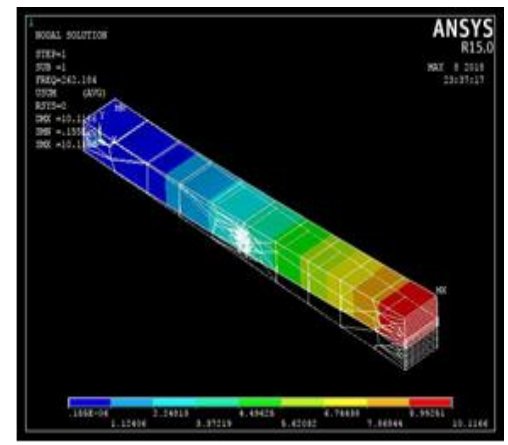

Fig. 16. 1st mode of aloevera with $d / b=0.4$

\section{CONCLUSION}

Comparison of vibration characteristics of flax, aloevera and sisal reinforced composite beams has been done in this work using Ansys software. Such practice of using natural fibres benefits in a sustainable growth ensuing eco-friendly policies. Flax fibre has the highest natural frequency followed by sisal fibre and aloevera fibre. Symmetric laminate has the highest natural frequency and is preferred over other special laminates because of its mechanical performance benefits. The natural frequency decreases with an increase in $E_{1} / E_{2}$ ratio. The effect of $E_{1} / E_{2}$ ratio is less pronounced in case of thin beams in comparison with thicker beams. The natural frequency decreases with an increase in aspect ratio of the three NFC beams considered. The effect of cut out plays a significant role in composite beams as the natural frequency decreases due to a reduction in stiffness caused by the loss of material.

\section{REFERENCES}

1. M. F. M. Alkbir, S. M. Sapuan, A. A. Nuraini, M. R. Ishak, "Fibre properties and crashworthiness parameters of natural fibre-reinforced composite structure: A literature review," Composite Structures, vol. 148, 2016, pp. 59-73.

2. T. G. Yashas Gowda, M. R. Sanjay, K. Subrahmanya Bhat, P. Madhu, P. Senthamaraikannan and B. Yogesha | Duc Pham (Reviewing Editor), "Polymer matrix-natural fiber composites: An overview," Cogent Engineering, vol. 5, 2018.

3. P. Peças, H. Carvalho, H. Salman, M. Leite, Natural fibre composites and their applications: A review. J. Compos. Sci. 2018, 2, 66.

4. Shuai Li, Tengteng Zheng, Qi Li, Yingcheng Hu, Bing Wang, Flexural and energy absorption properties of natural-fiber reinforced composites with a novel fabrication technique, Composites Communications, Volume 16, 2019, Pages 124-131.

5. Jin Zhang, Akbar Afaghi Khatibi, Erwan Castanet, Thomas Baum, Zahra Komeily-Nia, Philippe Vroman, Xungai Wang, Effect of natura fibre reinforcement on the sound and vibration damping properties of bio-composites compression moulded by nonwoven mats, Composites Communications, vol. 13, 2019, pp. 12-17.
6. Kin-tak Lau, Pui-yan Hung, Min-Hao Zhu, David Hui, Properties of natural fibre composites for structural engineering applications, Composites Part B: Engineering, vol. 136, 2018, pp. 222-233.

7. D. Aravind Kumar, G. Gokul Raj, G. Shivaani, V. M. Sreehari, Structural analysis of aircraft wings made of natural fiber reinforced composites, International Journal of Mechanical Engineering and Technology, vol. 9, 2018, pp. 1262-1268.

8. C. M. Meenakshi, Jeeva Bharathi, S. Karthikeyan, Experiment work on the effect of hygrothermal environment on the mechanical behaviour of natural fiber reinforced epoxy composites, International Journal of Engineering and Advanced Technology, vol. 8, 2019.

9. V. Ramesh, P. Anand, Evaluation on impact strength of basalt/kevlar fiber reinforced hybrid composite, International Journal of Engineering and Advanced Technology, vol. 9, 2019.

10. Guravtar Singh Mann, Lakhwinder Pal Singh, Pramod Kumar, Effect of Volume Fraction and Heating Temperature on Hybrid Natural Fibre Composites Developed Through the Die Moulding Process, International Journal of Engineering and Advanced Technology, vol. 9, 2019.

11. P. Thomas, M. P. Jenarthanan, and V. M. Sreehari, Free vibration analysis of a composite reinforced with aloevera fibres employing finite element and experimental techniques, Journal of Natural Fibres, Published Online (2018).

12. M. Rajesh, P. Jeyaraj, N. Rajini, Free vibration characteristics of banana/sisal natural fibres reinforced hybrid polymer composite beam. Procedia Eng, vol. 144, 2016, pp. 1055-1059.

\section{AUTHORS PROFILE}

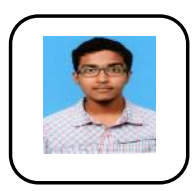

Thomas P, student of mechanical engineering at SASTRA Deemed University, has his area of interests Composite structures and vibration of systems. He has three conference papers in his credit in the area of Composite structures and has published work on natural fibre composites in International Journal of Natural Fibres.

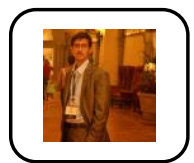

Sreehari VM is currently working as Senior Assistant Professor in SASTRA Deemed University, Thanjavur. He has published several international journal papers and presented over 10 international conferences. He is a member of Aeronautical Society of India, Institution of Engineers (India), and Indian Society of Theoretical and Applied Mechanics. His main interest lies in the field of aerospace structures, composite and smart structures, etc. 